\title{
O papel dos comerciantes nas políticas de ocupação do sertão matogrossense no século XVIII ${ }^{1}$
}

\section{Anna Beatriz Corrêa Bortoletto*}

Resumo: Durante o período de indefinição nas fronteiras entre as Américas portuguesa e espanhola, a atuação dos comerciantes foi essencial para a mudança de estilo na administração colonial portuguesa em meados do século XVIII, na área do sertão matogrossense. Através da análise de três pedidos organizados pelo Capitão Povoador Luis Rodrigues Vilares e encaminhados ao rei de Portugal pelo Ouvidor geral das minas do Cuiabá, verificaremos o papel desse mercador na articulação de uma rede de comerciantes em busca de maneiras alternativas para aumentar o volume de seu comércio. Tal questão é indissociável da transgressão dos limites fronteiriços e do contrabando feito sem a devida autorização do rei, desafiando as instruções reais a respeito da exploração territorial. Verificaremos como Vilares forçou a troca de mercadorias com as Missões espanholas de Moxos e Chiquitos e sua busca por novas rotas de comércio interno, através de caminhos que facilitassem o transporte de fazendas dentro da Colônia, analisando como sua capacidade de articular homens para concretizar seus projetos repercutiram na metrópole, forçando uma mudança nas políticas de proteção das fronteiras interioranas.

Palavras-chave: comércio de monções; contrabando; povoamento; sertão matogrossense; Tratados de limites.

\footnotetext{
${ }^{1}$ Agradeço a Lievin e Gabriel, por nunca me deixarem desistir; a Ulisses por me apoiar nas horas mais difíceis; e a Prof. ${ }^{a}$ Maria Aparecida de Menezes Borrego, que me introduziu nessas tramas da história.

* Graduanda do Bacharelado em História da Universidade de São Paulo. Bolsista PIBIC/CNPq. E-mail: anna.bortoletto@usp.br
} 


\section{artigos}

Anna Beatriz Corrêa Bortoletto

\section{Introdução}

O século XVIII foi um período de grande importância para a Coroa portuguesa no que diz respeito aos planos de exploração e expansão da colônia americana. A descoberta das minas de Cuiabá, em 1719, por Paschoal Moreira Cabral, deu início a um movimento de dilatação das fronteiras para o oeste, que possibilitou a ocupação de uma enorme porção de terra que ultrapassava claramente os limites acordados com a Coroa espanhola pelo Tratado de Tordesilhas ${ }^{2}$. A busca por ouro e outros metais preciosos levou muitos habitantes, principalmente oriundos de São Paulo, a uma vez mais encararem o sertão desconhecido em busca de riquezas, abrindo novos caminhos e estabelecendo rotas, vilas e povoações pelo interior da colônia setecentista. Tratava-se de uma área de intenso conflito, tanto entre os vassalos de ambas as Coroas ibéricas como entre os sertanistas, os grupos indígenas e os jesuítas que por ali habitavam. O sertão matogrossense foi uma área de intensa circulação apesar do clima considerado hostil pelos europeus que se instalaram na região - onde o encontro de práticas, técnicas e conhecimentos de diferentes culturas acontecia, gerando uma movimentação pelo processo de negociação, que acabou por resultar não na sobreposição de um conhecimento sobre o outro, ou numa relação de hierarquia centroperiferia, mas na formulação de um novo tipo de conhecimento (RAJ, 2015).

Abundante em minas de ouro e também de diamantes, tratava-se de uma região "com matos virgens de arvoredos muito elevado e corpulento, que entrando a penetral-o (sic), o foram appellidando Mato-Grosso: e este é o nome, que ainda hoje conserva toda aquelle districto" (FONSECA, 1866, p. 354). Além da busca pela tão desejada riqueza através da mineração, alguns homens - reinóis em sua maioria - aproveitaram esse momento de grande fluxo pelo território americano para acumularem fortunas por meio do trato comercial. No

\footnotetext{
${ }^{2}$ Cabe ressaltar que essa ocupação não se deu em território desocupado, mas em uma região onde circulavam diversos grupos indígenas. As relações estabelecidas entre os colonos e essas populações autóctones variaram muito e foram significadas e ressignificadas, passando desde a submissão religiosa até o confronto bélico, como foi o caso com os grupos Paiaguá e Bororo, guerreiros que dominavam as vias fluviais e estavam presentes na região onde foi estabelecida a Fazenda de Camapuã, propriedade ocupada por portugueses (HOLANDA, 2014, pp. 97-99;PRESOTTI, 2008. pp. 83-91).
} 


\section{artigos}

O papel dos comerciantes nas políticas de ocupação do sertão matogrossense no século XVIII

presente trabalho, verificaremos como um desses comerciantes, Luis Rodrigues Vilares, apoiado pela administração local, mobilizou sua rede de sociabilidade para influenciar o Conselho Ultramarino nas decisões sobre os métodos para garantir a posse dessas terras ocupadas além dos limites do Tratado de Tordesilhas. Desde pelo menos o início da década de 1740, os negociantes das minas do Cuiabá e Mato Grosso propõe ao Conselho Ultramarino a construção de feitorias ao longo dos rios que percorrem a região, tanto para proteção contra os espanhóis como para servir de entreposto comercial e ponto de contrabando com América espanhola. A princípio, o Conselho se posicionará contra as propostas apresentadas, mas veremos que a partir da segunda metade do século XVIII o modelo de fortalezas será posto em vigor, com as funções planejadas inicialmente pelos comerciantes. Assim, inferimos que a participação dos particulares na ocupação da América portuguesa não se deu somente através da prática, mas também teve papel fundamental nas discussões de projetos estratégicos pela Coroa e o Conselho Ultramarino. Cabe ressaltar que as fontes aqui utilizadas já foram tratadas por outros autores, como Sérgio Buarque de Holanda, Mario Clemente Ferreira, Francismar Alex Lopes de Carvalho e Thiago Kramer de Oliveira, mas não com o viés aqui apresentado.

\section{A função do comércio na expansão para o oeste}

O comércio foi essencial para a garantia da ocupação portuguesa no interior da colônia. A região das minas do Cuiabá e Mato Grosso era abastecida pelo comércio das monções paulistas, realizado através da navegação de rios e da travessia de varadouro ${ }^{3}$. A principal rota partia de Araritaguaba (atual Porto Feliz, nas proximidades de Itú), passando pelos rios Tietê, Paraná, Pardo, Paraguai e Cuiabá. As partidas aconteciam normalmente entre os meses de março e maio, época de cheia dos rios, podendo a viagem durar entre cinco e sete meses

\footnotetext{
${ }^{3}$ Varadouros são, pela definição de Raphael Bluteau $(1721$, p. 362) "a paragem em que se varão os navios em terra". No caso das monções do interior paulista, os varadouros eram os locais de travessia entre as cabeceiras de dois rios, nos quais era necessário realizar a passagem das canoas por terra, descarregando as cargas. 0 transporte era feito, em determinados casos, em carros de bois, e mais comumente pelos escravos. Alguns pontos de varação eram de longa extensão, e devido a quantidade de carga e ao número de canoas, o processo de travessia era lento, o que possibilitou o surgimento dos pousos e o desenvolvimento do comércio nesses locais.
} 


\section{artigos}

Anna Beatriz Corrêa Bortoletto

(HOLANDA, 2014, p. 108). Apesar das inúmeras cachoeiras a serem transpostas, da ameaça de ataque de povos indígenas não submetidos ao jugo cristão, da dificuldade em conseguir alimentação, entre outros obstáculos que o percurso apresentava, o empreendimento dos monçoeiros tinha grandes possibilidades de render altos lucros, dado que os preços cobrados pelas fazendas secas e molhadas na região mineradora do oeste paulista eram altos (pela escassez e dificuldade de abastecimento) e negociados diretamente com ouro em pó.

Nesse trajeto das monções destaca-se a Fazenda de Camapuã, pouso que se torna essencial para as expedições ${ }^{4}$. Estabelecida em um ponto de varação de canoas no trecho entre os rios Pardo e Taquari, ligando a bacia do Tietê com a do Paraguai, era ali que as tropas repousavam durante a difícil travessia. Tratava-se de um local garantido onde os navegantes podiam descansar da jornada e se alimentar novamente de carnes que não lhes dependesse da caça. A descoberta daquele trecho de terra diminuiu o tempo de travessia das monções (HOLANDA, 2014, p.91-2). A fazenda chegou a abrigar diversas autoridades, como o Governador da Capitania de São Paulo, Rodrigo César de Meneses, durante sua expedição de reconhecimento da região; o Conde de Azambuja; e os membros das expedições científicas, já no final do século XVIII e início do século XIX; até o seu declínio quando da completa substituição dos caminhos fluviais por rotas terrestres (ESSELIN, 2016, p.61). Assim como nas minas daquele sertão, na fazenda de Camapuã os preços cobrados por produtos alimentícios básicos, como feijão e toucinho, eram extremamente altos, podendo chegar a custar 16 e 32 oitavas de ouro cada, respectivamente (OLIVEIRA, 2015, p. 226). Desde 1727 o local era administrado pelo homem de negócios Luis Rodrigues Vilares, em parceria com seu sogro e o concunhado.

Vilares nasceu em São Mamede de Ferreira, lugar de Villares, concelho de Coura, no Arcebispado de Braga. Chegou à América Portuguesa provavelmente na década de 1720,

\footnotetext{
${ }^{4}$ Os pousos eram locais de passagem que se tornavam, por períodos determinados, ponto de fixação, criando uma relação ambígua entre o passageiro e o permanente (VIDAL, 2016).
} 


\section{artigos}

O papel dos comerciantes nas políticas de ocupação do sertão matogrossense no século XVIII

onde passou a atuar como comerciante ${ }^{5}$. Em São Paulo, casou-se com Angela Vieira, filha do também mercador reinol Manuel Veloso, com quem teve dois filhos: uma moça, que como a mãe casou-se com um comerciante reinol (BORREGO, 2010 p. 253) e um menino, que entrou para o serviço da Igreja. Apesar de seus passos iniciais na colônia indicarem uma maior proximidade com São Paulo, é na região mineradora do Cuiabá e Mato Grosso que Luis Rodrigues exercerá influência ${ }^{6}$. Como parte dos monçoeiros que atravessam de São Paulo para o interior, Vilares - além de exercer a atividade de comerciante - também organizava bandeiras que exploravam o sertão em busca de metais preciosos. Durante sua permanência na região, chega a receber o título de Capitão mor Povoador da localidade (Annaes do Senado da Câmara do Cuyaba 1719-1830, p. 60).

\section{O avanço em direção aos espanhóis}

Em 1736, uma destas expedições encaminhada por Vilares à Chapada dos Parecis região do rio Sararé, afluente do Guaporé, nas proximidades de onde mais tarde seria fundada a Vila Bela da Santíssima Trindade - encontra ouro na região e funda ali o Arraial de São Francisco Xavier (FONSECA, 1866, p. 354). É na vizinhança desse arraial, entre as cabeceiras dos rios Jauru e Guaporé, que em 1745, Luis Rodrigues - num projeto assinado por doze homens e que articula ainda outros moradores da região - pretende construir um varadouro, baseado no modelo da bem sucedida Fazenda de Camapuã (Projecto de abertura do caminho de Terra ou Varadouro desde o rio Jauru athe o rio Guapore na capitania do Cuyaba por Luis Roiz Vilares em MDCCXLIII). José Gonçalves da Fonseca, então secretário de Estado do

\footnotetext{
${ }^{5}$ Como o perfil traçado por Scott, Berute e Scott (2017), trata-se de um homem português vindo do norte do país ibérico, que se estabelece na colônia através do comércio e case-se com uma mulher nascida no Brasil, ligando-se a uma rede de sociabilidade preexistente, através do matrimônio com filhas de homens de negócios já estabelecidos na América. Não podemos afirmar que Luis Rodrigues Vilares chegou à colônia ainda enquanto jovem, como nos casos analisados pelos autores, mas tal afirmação não pode ser descartada.

${ }^{6}$ Era através de casamentos que as redes de comerciantes cresciam e se espalhavam ao redor da colônia. Luis Rodrigues Vilares inicialmente adere à rede mercantil do sogro, ligada a São Paulo, conforme nos mostra Maria Aparecida de Menezes Borrego (2010), mas como veremos, quando já estabelecido em Cuiabá, passa a articular com outros homens da região mineradora, originando novas redes sociais e de comércio. Tais redes possibilitam Vilares a ter contato com uma região cada vez maior do território português, expandindo suas conexões para o Grão-Pará e posteriormente para a Bahia.
} 


\section{artigos}

\section{Anna Beatriz Corrêa Bortoletto}

Maranhão, acusa Vilares e seu principal associado nesse projeto, João de Souza de Azevedo, de quererem tomar para si aquelas terras, pois se tratava de local "aonde já corria a fama, que havia diamantes" (FONSECA, 1866. p. 369). Tal conjectura não pode ser descartada, visto que mais tarde seriam encontrados diamantes na região (que passaria a ter acesso restrito devido ao monopólio real na extração desse bem precioso), mas - devido à trajetória de Vilares na região mineradora - acreditamos que os motivos comerciais foram a razão de tal empreitada. A ligação entre os dois rios, para além de facilitar o abastecimento das minas do Mato Grosso, representaria a ligação entre as bacias do Amazonas e do Prata, abrindo assim a possibilidade de uma nova rota de monção, partindo então não mais de São Paulo, mas do Grão-Pará. Outra oportunidade que um fácil acesso ao rio Guaporé traria à Vilares e seus associados seria a facilitação do contrabando que ocorria entre os comerciantes portugueses e as missões jesuíticas espanholas do Moxos e Chiquitos, e outras que se instalavam em ambas as margens do dito rio $^{7}$.

Já em 1738, Luis Rodrigues Vilares “invocava saber que aquelas missões [castelhanas de Moxos e Chiquitos], estavam próximas, pelo que seria conveniente conhecer a efectiva distância delas" com relação às povoações portuguesas, vigiando os padres e o eventual aumento dos aldeamentos para o que acreditavam ser então o lado luso da fronteira (FERREIRA, 2010, p.270). Na verdade, o que estaria por trás dessa expedição seria a primeira tentativa de Vilares em contrabandear produtos para os aldeamentos indígenas, estabelecendo assim uma forma de comércio com a América espanhola. O sistema de porto único adotado pela Coroa de Castela dificultava a chegada de produtos, principalmente europeus, às regiões interioranas da América espanhola, o que tornava atraente - para ambos os lados - esse comércio ilegal, que consistiria na troca de fazendas como tecidos, açúcar e vinhos portugueses por gados e cavalos das missões castelhanas (CARVALHO, 2011,

\footnotetext{
${ }^{7}$ Sobre o varadouro, não sabemos se de fato Vilares e os demais signatários do projeto conseguiram colocá-lo em prática, mas há informações de que anos mais tarde, em 1773, se realizavam obras naquela região com o fim de possibilitar a varação de canoas por terra (AHU_ACL_CU_010, Cx. 17. D. 1045).
} 


\section{artigos}

O papel dos comerciantes nas políticas de ocupação do sertão matogrossense no século XVIII

p. 599). Entretanto, Vilares não conseguiria sair com essa primeira expedição que planejava aos limites espanhóis, por intervenção do Intendente e Provedor da Fazenda Real, Manuel Rodrigues Torres.

No mesmo ano, uma bandeira a mando do Ouvidor geral das minas do Cuiabá, João Gonçalves Pereira, sai em direção ao Paraguai, com a mesma justificativa de averiguar a verdadeira distância entre as terras de Portugal e Espanha, e em busca de ouro. Ferreira (2010, p. 270) afirma que esta excursão seria uma resposta ao veto do Intendente - que mais tarde acabaria preso por ordem do Ouvidor geral (AHU_ACL_CU_010, Cx. 2. D. 131) - em relação aos planos de Luis Vilares. Apesar da iniciativa não ter tido sucesso em chegar às missões castelhanas, os oficiais da Câmara de Cuiabá informam ao Conselho Ultramarino que a "bandeira para a parte do Paraguay na deligencia de descobrir ouro, fora dar em huma aldea do gentio Aravirá, dos quaes apanhara alguns, e the acharam quatro machados de feitio de cunhas, q elles dicerão seremlhe dados pellos castelhanos" (AHU_ACL_CU_010, Cx. 3, D. 142). A notícia gera preocupação entre os conselheiros, pois indicava que a influência espanhola estava mais próxima das minas e povoações portuguesas.

Em consulta de 30 de janeiro de 1741 (AHU_ACL_CU_023, Cx. 3, D. 177) - em uma réplica a outra carta de João Gonçalves Pereira, encaminhada ao Conselho Ultramarino com um "auto summario perguntando por elle quatorze testemunhas pellas quaes se provava a distancia que há daquella Villa, e povoaçoens de seu destrito, a algumas de Hespanha" - o Conselho Ultramino responde sobre os apontamentos feitos pelo Ouvidor a respeito da necessidade de proteger o espaço português. Ele teria sugerido levantar fortalezas no Rio Cuiabá, que deveriam ser acompanhadas de pelo menos duas companhias de infantaria; e proposto que a Coroa desse aos moradores das minas do Cuiabá favores nos tributos e direitos de entrada, com a finalidade de atrair à localidade um maior número de habitantes. Os conselheiros concordam com a necessidade de assegurar o território português:

mas para que a Fortaleza, que o Ouvidor aponta, seria naquella paregem de muita despeza, e pouca utelidade, pois com ella serão feitas todas as portas 


\section{artigos}

\section{Anna Beatriz Corrêa Bortoletto}

por onde se pode entrar, e para subsistência da Fortaleza he necessaio demaes do Prezidio de Soldados estabalecimento de moradores na sua vizinhança (AHU_ACL_CU_023, Cx. 3, D. 177).

A proposição do Conselho é que então se garanta a posse do sertão cuiabano através da construção de novas povoações e de uma nova vila, que teria por tempo determinado diversos benefícios e isenções, para que se atraíssem àquela região longínqua novos habitantes - parecer este com o qual o rei concorda e manda consultar os Governadores de São Paulo e Rio de Janeiro a respeito dos benefícios a serem concedidos aos moradores da nova localidade a ser criada. É o princípio de uti possetis que começa a ser posto em prática anos antes da negociação do Tratado de limites que seria assinado pelos reis ibéricos em 1750.

\section{Os pedidos dos comerciantes}

Porém, antes mesmo de receber o dito Parecer do Conselho Ultramarino, os comerciantes e moradores da Vila de Cuiabá, liderados por Luis Rodrigues Vilares e intermediados pelo Ouvidor geral, encaminham à Portugal três pedidos no dia 20 de setembro de 1740. No que chamaremos aqui de primeiro abaixo-assinado (AHU_ACL_CU_010, Cx. 3, D. 140), os sertanistas partem de uma articulada argumentação pedindo novamente ao rei que os permita "a sua custa fazer sobre o Rio Paraguai grande nas partes em que aponta o dito Doutor Ouvidor Geral ou nas que parecerem mais convenientes algumas feitorias com baluartes e neles artilharia [...]" para proteção das terras adquiridas em favor do reino e pela facilitação da inserção de mercadorias portuguesas nas missões castelhanas.

A fim de justificar tal empreitada, os comerciantes e moradores da Vila de Cuiabá que assinam o pedido alegam a

diminuição muito grande nos seus cabedais empregados em fazendas por não poderem dar-lhes saída nas ditas minas e do que têm dado a algumas estão por embolsar da maior parte do seu produto por o estado da terra assim o permitir; o que procede do diminuto número de moradores, e falta de ouro por não haver quem o procure e tire motivos ambos para a total ruína dos negócios(AHU_ACL_CU_010, Cx. 3, D. 140).

É no comércio com a América Espanhola "necessitado das fazendas e mais gêneros que 


\section{artigos}

O papel dos comerciantes nas políticas de ocupação do sertão matogrossense no século XVIII

os suplicantes conduzem a estas Minas para negócio" que eles enxergam uma solução tanto para o aumento de suas finanças como para o problema da falta de povoadores nas regiões sertanejas, pois que outros homens seriam atraídos àquelas minas ao perceberem a nova oportunidade de ganhos que o comércio entre os habitantes das duas Américas poderia trazer, "com o que se aumentarão as povoações nestes dilatados estados de V. M.; e terá multiplicados direitos a Real Fazenda tanto nas alfândegas dos portos marítimos, como nas destes sertões". Assim, avisam da saída de uma nova bandeira em julho daquele ano sob a justificativa de que finalmente se pudesse saber a verdadeira distância entre os domínios portugueses e castelhanos. A dita bandeira chegará ao seu destino com uma carta aos Padres Missionários enviada por Vilares propondo a abertura das relações comercias (AGI Charcas 425; FERREIRA, 2010, p. 271). Ainda neste primeiro abaixo-assinado, Vilares e seus associados pedem que a Coroa colabore com o suprimento de pólvora e armas para socorro do povo.

Os diversos pontos presentes nos pedidos do primeiro abaixo-assinado são justificados com base em capítulos dos Regimentos do Vice Rei datado de 1677 e do Governador do Rio de Janeiro de 1679. Tais regimentos falam em pressionar o comércio com os espanhóis via Rio da Prata, trocando bens europeus portugueses pelos metais preciosos americanos exportados pela Espanha. Baseados neles, os comerciantes usam do exemplo da colônia de Sacramento como modelo a ser seguido no interior oeste da América portuguesa. Pedem ainda que, quando da efetiva construção das fortalezas que permitirá extrair riquezas dos castelhanos,

no caso que além dos suplicantes venha algum terceiro que à sombra das ditas feitorias queira fazer ver-se o seu negócio seja sempre com a obrigação de pagar aos suplicantes a mesma comissão de dez por cento, porque como os suplicantes a V. M. para fazerem à custa de suas fazendas as sobreditas defesas por esta razão parece devem ter a esperança de que $V$. M. se digne fazer-Ihes a mercê que pedem, concedendo-lhes que só eles possam usar das ditas feitorias e embarcações com artilharia montada, e no caso que haja outros comerciantes que recebam de V. M. a mercê que os suplicantes pedem sempre estes a recebem de V. M. pagando comissão do seu negócio(AHU_ACL_CU_010, Cx. 3, D. 140). 


\section{artigos}

\section{Anna Beatriz Corrêa Bortoletto}

Este primeiro abaixo-assinado chega ao Conselho Ultramarino e será posto junto com a matéria que discute os meios de proteção do território português, que acaba por gerar dois pareceres principais. Um, datado de 05 de abril de 1742 (AHU_ACL_CU_010, Cx. 3, D. 196, anexo; AHU_ACL_CU_010, Cx. 3, D. 140, anexo), é expedido enquanto se aguarda o parecer dos Governadores sobre o melhor meio de se proteger a região. Recomenda o fim das expedições aos domínios espanhóis, para evitar inquietar os castelhanos e sugere ainda a proibição de qualquer tipo de comunicação entre os vassalos das duas Coroas por não haver modo seguro de realizá-las. A resposta definitiva sobre o melhor modo para se realizar a defesa do território português se dará apenas em 26 de abril de 1746, quando - apoiado pelo parecer de D. Luis Mascarenhas, Governador de São Paulo - o Conselho recomenda seguir-se o primeiro parecer dado em 30 de janeiro de 1741, que apóia a garantia dos domínios através do povoamento. Apesar de Gomes Freire de Andrade, Governador do Rio de Janeiro, ter se posicionado a favor da construção de fortalezas pelos rios de fronteira, juntamente com o provedor da Fazenda real, o Conselho as via como intempestivas.

Ora, esse último parecer de 1746, trata de reassegurar a proibição do trato comercial entre os vassalos portugueses e espanhóis, aplicando penas severas aos infratores. O próprio Luis Rodrigues Vilares viria a ser expulso das minas do Cuiabá nesse mesmo ano, por uma nova tentativa de contrabandear suas fazendas nos domínios castelhanos (AHU_ACL_CU_02301, Cx. 16, D. 1599 e Siarq: (cm/SBH) Pi 482/22:221 p.30). O Conselho Ultramarino estabelece que não se deve mais misturar outras questões com a matéria de conservação e proteção dos domínios portugueses na região da fronteira, que se dará a partir da construção de uma nova Vila. Daí surge a Provisão Régia de 05 de agosto de 1746 que pelas contas “que me deu João Gonçalves Pereira e attendendo a informação que nella me destes [...] mandar erigir huma vila no districto de Mato-Grosso" (AHU_ACL_CU_017-01, Cx. 65, D. 15194), sobre a qual falaremos adiante.

Além deste primeiro abaixo-assinado, Luis Rodrigues Vilares articulará os moradores da Vila Real do Senhor Bom Jesus de Cuiabá em outros dois pedidos. O que chamamos de 


\section{artigos}

O papel dos comerciantes nas políticas de ocupação do sertão matogrossense no século XVIII

segundo abaixo-assinado (AHU_ACL_CU_010,Cx. 3, D. 141) é relativo aos direitos de entradas das cargas naquelas minas, sobre os quais um novo contratante tentava estabelecer um tipo de cobrança que não era a usualmente aplicada aos produtos que saiam de São Paulo rumo às minas e vilas do sertão paulista. Usando uma argumentação baseada principalmente nos costumes; realçando as dificuldades de levar mercadorias de São Paulo até aqueles interiores, pedem a manutenção do sistema como era feito desde seu início - com a cobrança realizada em Cuiabá, e não em Araritaguaba, e o pagamento das taxas com base em 3 arrobas e não em 2 (como se dava no restante das minas da colônia) - devido à ameaça de ataques indígenas na rota das monções e da perda ocasional de mercadorias ao longo do trajeto.

Os comerciantes aproveitam este pedido para mais uma vez falar sobre a necessidade de se construir feitorias nos rios dali "para com ellas se abrir comercio com os castilhanos e gentios." Em seu parecer sobre as intenções dos comerciantes, o Ouvidor João Gonçalves Pereira (que viria a arrematar os contratos de direitos de entrada no ano de 1743) diz ser justo o pedido daqueles homens "porque alem de todos os riscos, q os suplicantes pondirão, há outro mayor, que he a do gentio, q tem chegado a destruir, e acabar tropas inteiras dentros do ditto Rio Coyabá, razão porque se deve fazer o registro em parte conveniente". Além de ajudar na garantia do território e na luta contra os vassalos da Coroa rival, as fortalezas também ajudariam na redução dos indígenas à Coroa portuguesa e à Igreja.

O terceiro abaixo-assinado (AHU_ACL_CU_010,CX.3, D. 139), firmado pelos moradores da Vila de Cuiabá, pede a construção de uma Casa de Misericórdia na comarca pois que muitos têm "perdido a saúde nos dilatados sertões dessas conquistas, navegando perigozos rios e atraveçando Mattos, serranias, e campos pelo discurso de mezes e annos inteyros padecendo grandes fomes por falta de sustento"; e o envio de padres missionários à região para atender o "numerozo gentio bravo, a que não tem chegado a luz da fé por falta de missionários, que athe o prezente não pasarão a estas conquistas de que tem rezultado grande prejuízo ao serviço de Deos, e a estenção dos domínios de V. Mage." Segundo Gonçalves Pereira, em seu 


\section{artigos}

Anna Beatriz Corrêa Bortoletto

parecer, a construção das feitorias mencionadas nos dois outros pedidos feitos na mesma data serviam inclusive para atender estes pontos, pois que se poderia "applicar hum por cento do rendimento dellas para ajuda da côngrua sustentação dos Misionarios, e outro para a Misericordia, e hospitalidade dos enfermos pobres."

\section{Os modelos implementados para proteção do sertão}

Percebemos que o intento dos comerciantes, tendo Luis Rodrigues Vilares e João Gonçalves Pereira como figuras-chave, de construir feitorias nos rios da região de fronteira entre a América das duas Coroas ibéricas - e consequentemente abrir comércio com as missões castelhanas do Moxos e Chiquitos - teve um importante peso na discussão do Conselho Ultramarino sobre como proteger aquele sertão paulista cada vez mais dilatado e ameaçado pelo inimigo ibérico. Dois meios principais foram apontados como solução para defesa do território português: a construção de fortalezas, modelo defendido pelos comerciantes da região (com apoio de autoridades locais e do então governador do Rio de Janeiro, Gomes Freire de Andrada); e o povoamento, proposto naquele momento pelo Conselho Ultramarino (com apoio do Governado de São Paulo, D. Luis Mascarenhas) e aceito pelo rei D. João $V$ na década de 1740.

Ambos os métodos seriam postos em prática ao longo do século XVIII, sendo que na segunda metade os dois são utilizados concomitantemente pelos administradores reais. Como mencionado anteriormente, o parecer do Conselho Ultramarino escrito em 26 de abril de 1746 tem como desdobramento a emissão de uma Provisão régia editada naquele mesmo ano que ordena a fundação de uma vila "no districto do Matto Grosso em o sitio que se julgar mais conveniente o qual da parte do Cuyabá tenha por termo o Cubatão dezembocadouro do rio Jacorú [Jauru]", na qual os habitantes terão por período determinado de tempo diversas regalias como a isenção de uns e a diminuição de outros tributos e a não execução de eventuais dívidas (AHU_ACL_CU_017-01, Cx. 65, D. 1519.). Nasce daí Vila Bela da Santíssima Trindade, que será fundada a cinqüenta léguas da boca do rio Jauru, em 1752, pelo 


\section{artigos}

O papel dos comerciantes nas políticas de ocupação do sertão matogrossense no século XVIII

Governador da recém-criada Província do Mato-Grosso, D. Antonio Rolim de Moura, da qual será a Capital (Auto da Fundação da Villa Bella da SS. Trindade do Mato Grosso, p. 191-2).

Apesar dos pedidos dos comerciantes de Cuiabá para realizarem a construção de feitorias às margens dos rios da região não ter sido aceito de imediato pelo Conselho Ultramarino e a Coroa, na segunda metade dos setecentos o sistema de fortalezas vigorará nos Rios Paraguai e Guaporé, tendo como principais representantes os fortes de Nova Coimbra (no atual Mato Grosso do Sul) e Príncipe da Beira (localizado no que hoje é o Estado de Rondônia). Este último, desde sua construção, serviu como ponto de contrabando entre as duas Américas (CARVALHO, 2012, p. 98; 2011, p. 605), tendo inclusive sido construído com materiais que vieram do lado espanhol.

Os fortes fizeram parte de um plano de urbanização da colônia dirigido por Sebastião José de Carvalho e Melo, o Marquês de Pombal (ARAÚJO, 2012, p.49ss). Foram um marco da fixação portuguesa nos rincões da América e funcionavam como símbolo do poder português na expansão para territórios além da fronteira demarcada no Tratado de Madri, este não mais em vigor desde o reinício das hostilidades entre portugueses e espanhóis (FERREIRA, 2011. p. 8). Serviram ao propósito de uti possetis, da posse pelo uso, que marcava os Tratados de limites que foram negociados entre as monarquias ibéricas ao longo da segunda metade do século XVIII. Ao redor dos fortes, os portugueses instalavam povoações que contavam com casas não só para os colonos portugueses, mas também para os indígenas que se tornassem súditos do Rei Fidelíssimo. Mesmo com a nova política indigenista que passava a vigorar no Brasil colônia e com os incentivos dados pelas autoridades administrativas para atrair novos habitantes para o interior, o problema da população dispersa persistiu, o que fica evidente nas observações enviadas pelo engenheiro militar responsável pela construção do Forte Príncipe da Beira, nas suas Reflexões sobre a Capitania do Mato Grosso, ao então Governador do Mato Grosso, João de Albuquerque de Mello Pereira e Cáceres:

fica evidente, digo, que todos os habitantes capazes de pegar em armas n'esta capital do Matto Grosso e Cuyabá serão todos elles necessários para a 


\section{artigos}

\section{Anna Beatriz Corrêa Bortoletto}

vigorosa defensa do Guaporé, suppondo-o atacado ao mesmo tempo pelas duas distancias de Chiquitos e de Moxos, sem que haja outros vassalos que vão preenchendo as diárias perdas de gente que a guerra consome (FERREIRA; SERRAS, 1849, p. 383)

Na América em disputa, essas fortalezas serviram como modelo de atração para que os povos nativos se juntassem às Coroas europeias (CARVALHO, 2012, p.89). Garantir a presença dos indígenas como súditos em locais permanentes era essencial para que se garantisse de fato a ocupação e a consequente posse da terra. Além da força bélica frente ao inimigo, os fortes demonstravam o poder de conquista da terra e de redução do gentio à Coroa e à Igreja. No lado português da América, os povos naturais eram desde o século XVI usados no processo de dilatação das fronteiras, mas com as mudanças no regimento dos indígenas, seu papel foi alterado, tornando-os participantes mais ativos da disputa territorial entre as duas Coroas ibéricas. Como nas primeiras fortificações portuguesas ao longo das costas estrangeiras, os Fortes de Nova Coimbra e Príncipe da Beira tinham como alvo principal o inimigo europeu, e não os povos autóctones. Ademais - como na Ásia as fortalezas deveriam garantir o controle da navegação nos oceanos -, nos rios Paraguai e Guaporé elas deveriam servir como garantia de navegação exclusiva portuguesa nas rotas fluviais das respectivas baías.

O imaginário cristão é indissociável da expansão portuguesa pelo mundo. A colonização lusitana, tanto nas ocupações orientais como no Brasil, tiveram uma justificativa mística ${ }^{8}$. Desde o século XVI, vemos a defesa de que era em terras brasileiras se encontrava paraíso terreal, na localidade chamada de Lagoa Xarayes ${ }^{9}$. Mesmo no século XVIII, período em que a colonização passa por um novo projeto ilustrado - que visa à urbanização e equilíbrio da

\footnotetext{
${ }^{8}$ Já no século XV, D. Manuel defendia que a Reconquista de Jerusalém se daria pelas rotas comerciais do Índico, passando pelo Mar Vermelho até que o inimigo infiel fosse derrotado e a terra santa retomada para os povos católicos (DORÉ, 2010, pp. 66-7).

${ }^{9}$ Há uma longa discussão teológica-científica em vigor durante os séculos XVII e XVIII sobre a Lagoa Xaerez, o paraíso terreal e o mito da ilha-Brasil. Seus principais expoentes, com quem os comerciantes do sertão paulista têm contato através da leitura, são o padre Simão de Vasconcellos - autor das Noticias curiosas e necessárias das cousas do Brasil - e o fundador da Academia dos Esquecidos, Sebastião Rocha Pita - autor da História da América Portuguesa. (DOMINGUES, 1999; KANTOR, 2007).
} 


\section{artigos}

O papel dos comerciantes nas políticas de ocupação do sertão matogrossense no século XVIII

balança comercial em favor de Portugal - essa noção continua presente. Luis Rodrigues Vilares também se apropria deste imaginário português, através da leitura da obra Noticias curiosas e necessárias das cousas do Brasil, e coloca como justificativa de seu já mencionado projeto de construção de um varadouro entre as nascentes do Jauru e Guaporé, a busca pela mítica Lagoa e a ligação fluvial que separaria a América em duas. Durante o projeto de construção dos fortes nos rios Guaporé e Paraguai, buscava-se ainda o controle deste ístimo que permitiria a delimitação da Ilha-Brasil.

\section{Conclusão}

Por último, é importante ressaltar que os fortes construídos nos rios de fronteira brasileira tiverem um papel importante não só para a administração colonial, que garantiu um maior controle sobre a região em disputa, mas também para a atividade comercial exercida nos sertões do interior matogrossense. Como vimos, o forte de Príncipe da Beira foi construído com o apoio do contrabando entre portugueses e espanhóis e serviu por muitos anos como ponto estratégico de desvio de bens da Coroa Espanhola para o território português. Já o forte de Nova Coimbra foi construído em área pouco fértil, o que impedia sua autossuficiência. Acreditamos que esse erro abriu mais uma rota comercial para os comerciantes baseados em Cuiabá, que passaram a ser responsáveis pelo suprimento de grãos e outras fazendas para a fortificação.

Luis Rodrigues Vilares não viu suas idéias serem postas em prática, pois ele morre em janeiro de 1769 (Annaes do Senado da Câmara do Cuyaba 1719-1830, p. 60), mas elas circularam na América portuguesa e não passaram despercebidas pelo Conselho Ultramarino. Sua habilidade de colocar homens em movimento para ver suas demandas atendidas chamou a atenção de autoridades, mesmo após sua morte, quando seus papéis sabidamente o Projecto de abertura do caminho de Terra ou Varadouro desde o rio Jauru athe o rio Guapore na capitania do Cuyaba por Luis Roiz Vilares em MDCCXLIII - circulam pela colônia chegando às mãos do então Governador de São Paulo D. Luis Antônio de Souza Botelho Mourão, o Morgado de Mateus, e do engenheiro militar Brigadeiro José Custódio de Sá e 


\section{artigos}

\section{Anna Beatriz Corrêa Bortoletto}

Faria, participante da Primeira Expedição Científico-Demarcatória do Tratado de 1750 entre Portugal e Espanha sobre os limites territoriais de ambas as Coroas na América. O comércio com os aldeamentos espanhóis que Luis Rodrigues tanto forçou na década de 1740 e as fortalezas que ele e João Gonçalves Pereira tanto insistiram na construção se tornaram uma realidade na década de 1770 .

Os comerciantes, com o apoio de autoridades locais, como foi o caso aqui apresentado, incentivaram no final da década de 1730 e início da década de 1740 a discussão que mais tarde definiria os modelos adotados pela burocracia portuguesa para ganhar influência e garantir a posse de um maior território em relação ao espaço ocupado pelos espanhóis durante as negociações dos Tratados sobre a divisão das Américas entre as Coroas ibéricas.

\section{Fontes Manuscritas}

AGI CHARCAS 425 Copia de La carta de Luys Roys Vilares escrita em Cuiabá em 22 de junho deste año de 1740 a los P.s miconeiros de Chiquitos solicitando La yntroducuion de su comercio por estas partes en peru.

AHU_ACL_CU_003, Cx. 7, D. 662. CARTA do ouvidor de Cuiabá, João Gonçalves Pereira, ao rei [D. João V], sobre a informação pedida pelo superintendente das minas de Goiás, Agostinho Pacheco Teles, se pela parte da vacaria se poderia introduzir algum socorro de cavalos na colônia; informando sobre a importância do comércio com os índios guaicurú, que podem colaborar na observação dos espanhóis e no combate ao gentio paiaguá. Anexo: informação (cópia). 1739, Setembro, 8, Cuiabá.

AHU_ACL_CU_010, Cx. 2. D. 131. CARTA do Intendente e Provedor da Fazenda Manoel Rodrigues Torres ao rei [D. João V] sobre as injustiças feitas pelo Ouvidor João Gonçalves Pereira e a maneira ilegal como foi preso sem culpa formada. Anexo: 14 doc, 1740, fevereiro, 20.

AHU_ACL_CU_010, Cx. 3, D. 139. CARTA do ouvidor João Gonçalves Pereira ao rei [D. João V] sobre o pedido dos moradores da Vila de Cuiabá do estabelecimento de uma igreja da Misericórdia que sirva também de hospital e que lhe seja atribuído parte dos dízimos da comarca e pede ainda o envio de missionários. Anexo: 2 representações e consulta. 1740, Setembro, 20, Vila de Cuiabá

AHU_ACL_CU_010, Cx. 3, D. 140. CARTA do ouvidor João Gonçalves Pereira ao rei [D. João V] sobre a pretensão dos comerciantes da Vila de Cuiabá de estabelecerem feitorias nas 


\section{artigos}

O papel dos comerciantes nas políticas de ocupação do sertão matogrossense no século XVIII

margens do rio Paraguai Grande e abrir comércio com os castelhanos do reino do Peru e Província do Paraguai. Anexo: 4 doc. 1740, Setembro, 20, Vila de Cuiabá

AHU_ACL_CU_010, Cx. 3, D. 141. CARTA do ouvidor João Gonçalves Pereira ao rei [D. João V] sobre o pedido dos comerciantes da Vila de Cuiabá relativo aos direitos das entradas das cargas. Anexo: 3 doc. 1740, Setembro, 20, Vila de Cuiabá

AHU_ACL_CU_010, Cx. 3, D. 142. CONSULTA do Conselho Ultramarino ao rei D. João V sobre a saída de uma bandeira para a parte do Paraguai e do encontro com uma aldeia do gentio Aravirá, que tinha em sua posse ferramentas dadas pelos castelhanos. 1740, Novembro, 10, Lisboa

AHU_ACL_CU_010, Cx. 3, D. 146. CARTA do ouvidor João Gonçalves Pereira ao rei [D. João V] sobre as entradas nas terras de Castela. 1740, Dezembro, 4, Vila de Cuiabá

AHU_ACL_CU_010, Cx. 3, D. 196. CONSULTA do Conselho Ultramarino ao rei D. João V sobre a conta que deu o ouvidor da Vila de Cuiabá a respeito da distância que há daquela vila e suas povoações às Indias de Espanha com que confinam aqueles sertões. Anexo: 3 doc. 1746, Abril, 26, Lisboa

AHU_ACL_CU_017-01, Cx.65, D. 1519. PROVISÃO régia pela qual foram concedidos diversos privilégios, prerrogativas, isenções de direito e liberdades aos moradores de uma nova Vila que se mandara fundar no distrito de Mato Grosso. 1746, agosto, 5, Lisboa

AHU_ACL_CU_023, Cx. 3, D. 177. CONSULTA do Conselho Ultramarino ao rei D. João V sobre a averiguação feita pelo ouvidor da comarca de Cuiabá, João Gonçalves Pereira, a respeito da possibilidade de invasão da região pelos espanhóis da fronteira próxima àquela vila. 1741, Janeiro, 30, Lisboa.

AHU_ACL_CU_023-01, Cx. 16, D. 1599. CARTA do (governador e capitão-general da capitania de São Paulo), D. Luís Mascarenhas a (D. João V), pedindo que ordene ao ouvidor da comarca do Cuiabá (Manuel Antunes Nogueira) que remeta para o povoado Luís Rodrigues de Vilares porque pretendia meter fazendas nos domínios de Castela, encobrindo a sua intenção com o pretexto de caridade em acudir ao próximo; e João Oliveira Cardoso que cobrou no Rio de Janeiro e fugiu para o Cuiabá e é um "revoltoso". Anexo: 2 cartas 1746, Junho, 03, Vila e praça de Santos.

Siarq (cm/SBH) Pi 400/18:83 P28.Anotações do relato "Projeto da abertura do caminho de terra, ou varadouro, tirado desde o Rio Jauru até o Rio Guaporé na Capitania do Cuiabá" de Luis Rodrigues Vilares, referindo-se as dificuldades encontradas no sertão, dentre os que assinaram o documento, encontrava-se o Capitão João de Sousa de Azevedo. Cuiabá, 23 fev.1743. s.ref. 7p. Campinas: Unicamp.

Siarq: (cm/SBH) Pi 482/22:221 P30Ordem Régia ao Governador Capitão General da Capitania de São Paulo, por intermédio de Thomé Joaquim da Costa Corte Real e Antonio Freire de Andrade Henriques, Conselheiros do Conselho Ultramarino respondendo e apoiando a carta na qual o governador informou a expulsão de Cuiabá, de Luiz Roiz Vilares e João de Oliveira, 


\section{artigos}

\section{Anna Beatriz Corrêa Bortoletto}

que inquietavam as minas e favoreciam contatos com os castelhanos. Lisboa, 25 abr.1747. 2p. Campinas: Unicamp.

Projecto de abertura do caminho de Terra ou Varadouro desde o rio Jauru athe o rio Guapore na capitania do Cuyaba por Luis Roiz Vilares em MDCCXLIII, 1743. São Paulo, Biblioteca Mario de Andrade, Coleção de Obras Raras e Especiais, Mss. 43.

\section{Fontes impressas}

Annaes do Sennado da Camara do Cuyabá: 1719-1830 [transcrição e sua organização Yumiko Takamoto Suzuki]. Cuiabá, MT : Entrelinhas ; Arquivo Público de Mato Grosso, 2007

Auto da Fundação da Villa Bella da SS. Trindade do Mato Grosso, em 19 de março de 1752in RIGHB. n. 216. p. 191-194 jul-set. 1952

BLUTEAU, R. Vocabulário português e Latino (T-Z). v. 08. Lisboa: Paschoal Silva, 1721.

FERREIRA, Joaquim José; SERRA, Ricardo Franco de Almeira. Reflexões sobre a capitania do Matto Grosso In RIHGB. Tomo XII. v. 12. p. 377-399. 1849

FONSECA, José Gonçalves da. Notícia da situação de Mato-Grosso e Cuyabá: estado de umas e outras minas e novos descobrimentos de ouro e diamantes. In RIHGB. Tomo XXIX - Parte Primeira n. 29(31). p. 352-390. 1866.

Instrucções dadas pela Rainha ao Governador da capitania de Mato-Grosso D. Antonio Rolin de Moura em 19 de janeiro de 1749. In RIHGB. Tomo LV - Parte I. n.55(85). p. 381-393. 1892

\section{Referências Bibliográficas}

ALMEIDA, André Ferrand de. A viagem de José Gonçalves da Fonseca e a cartografia do rio Madeira (1749-1752). Anais do Museu Paulista. São Paulo. v.17. n.2. p. 215-235. jul.- dez. 2009.

ARAUJO, Renata Malcher. A urbanização da Amazónia edo mato Grosso no século XVIII: Povoações civis, decorosas e úteis para o bem comum da coroa e dos povos. Anais do Museu Paulista. São Paulo, v.20. n.1, p. 41-76. jan-jun. 2012.

BELLOTTO, Heloísa Liberalli. Itinerário documental do Morgado de Mateus e o Projeto Resgate. Texto baseado na fala apresentada em vídeo no Seminário Em nome d' El Rey: $2^{\circ}$ seminário comemorativo dos 250 anos do governo do Morgado de Mateus. Arquivo Público do Estado de São Paulo, São Paulo, 20 de maio de 2015.

BORREGO, Maria Aparecida de Menezes. A teia mercantil: negócios e poderes em São Paulo colonial (1711-1765). São Paulo: Alameda; Fapesp, 2010.

BUENO, Beatriz P. Siqueira. Decifrando mapas: sobre o conceito de "território" e suas vinculações com a cartografia. Anais do Museu Paulista.São Paulo, v.12, p.193-234, jan-dez. 2004 


\section{artigos}

O papel dos comerciantes nas políticas de ocupação do sertão matogrossense no século XVIII

. Do borrão às aguadas: os engenheiros militares e a representação da Capitania de São Paulo. Anais do Museu Paulo. São Paulo, v.17, n.2, p.111-153, jul-dez. 2009

CARVALHO, Francismar Alex Lopes de. Rivalidade imperial e comércio fronteiriço: aspectos do contrabando entre as missões espanholas de Mojos e Chiquitos e a capitania portuguesa de Mato Grosso (c. 1767-1800). Antíteses, v. 4, n. 8, p. 595-630, jul./dez. 2011.

. Com despesas próprias a bem do Real Serviço: funcionários, colonos e a defesa da fronteirano extremo oeste da América portuguesa, c. 1750-1800. História (São Paulo), v.33, n.1, p. 171-194, jan./jun. 2014.

- Lealdades negociadas:povos indígenas e a expansão dos impérios ibéricos nas regiões centrais da América do sul (segunda metade do século XVIII). São Paulo, Universidade de São Paulo, 2012.

DOMINGUES, Beatriz H. A Filosofia e Ciência Modernas nos escritos do Padre Simão de Vasconcelos In Numen: revista de estudos e pesquisa da religião. Juiz de Fora, v. 2, n.2, 1999, p. 105-139

DORÉ, Andréa. Sitiados: os cercos às fortalezas portuguesas na Índia. São Paulo: Alameda, 2010

ESSELIN, Paulo Marcos. A fazenda Camapuã. Cadernos Lepaarq. Vol. XIII, n. 26, p.48-65, 2016.

FERREIRA, Mario Clemente. Colonos e Estado na revelação do espaço e na formação territorial de Mato Grosso no Século XVIII: notas de uma investigação. Actas do Congresso Internacional Espaço Atlântico de Antigo Regime: poderes e sociedades. Lisboa, 2005.

. O conhecimento da área de fronteira entre Mato Grosso e a América Espanhola no século XVIII: a procura de informações geográficas e cartográficas por portugueses e castelhanos. In OLIVEIRA, Francisco Roque de; Mendoza Vargas, Héctor. Mapas de metade do mundo: a cartografia e a construção territorial dos espaços americanos, séculos XVI a XIX. Lisboa: Universidade de Lisboa; Cidade do México: Universidade Autónoma do Mexico, 2010, p. 267-297.

. A disputa ibérica pelo domínio do rio Paraguai na segunda metade do século XVIII e a sua representação cartográfica. Anais do I Simpósio de Cartografia Histórica. Paraty, 2011.

HOLANDA, Sérgio Buarque de. Monções e Capítulos de Expansão Paulista; organização de Laura de Mello e André Sekkel Cerqueira. 4ª ed., São Paulo: Companhia das Letras, 2014.

KANTOR, Iris. Usos diplomáticos da ilha-Brasil: polêmicas cartográficas e historiográficas In Varia Historia, Belo Horizonte, v. 23, n. 37. p. 70-80. jan-jul 2007

OLIVEIRA, Tiago Kramer de. O capital mercantil no centro da América do Sul e as fronteiras do comércio na América colonial (primeira metade do século XVIII). Revista de Indias, vol. LXXV, n. ${ }^{\circ} 265$, p. 681-710, 2015a. 


\section{artigos}

\section{Anna Beatriz Corrêa Bortoletto}

Por uma cartografia da conquista: espacializações portuguesas no centro da América do Sul (1718-1752). Anais do I simpósio brasileiro de cartografia história. Paraty, 2011.

. Roças, Fazendas, Engenhos, Currais: Uma Cartografia Da Ruralidade Colonial Nas Minas Do Cuiabá (Primeira Metade Doséculo XVIII). Revista de História (São Paulo), n. 173, p. 211-251, jul.-dez., $2015 b$.

PRESOTTI, Thereza Martha. Na trilha das águas. Índios e Natureza na conquista colonial do centro da América do Sul: Sertões e Minas do Cuiabá e Mato Grosso (Século XVIII). Brasília, Universidade de Brasília: 2008

SCOTT, A.; BERUTE, G. S.; e SCOTT, D. Negócios em Família. Migração, comerciantes portugueses e suas redes (Porto Alegre / Rio Grande de São Pedro, séculos XVIII e XIX). In Acervo. Rio de Janeiro, v. 30, n. 1, p. 105-120. jan/jun 2017

SOUZA, Laura de Mello e. Formas provisórias de existência: a vida cotidiana nos caminhos, nas fronteiras e nas fortificações. In: SOUZA, Laura de Mello e (org.). História da vida privada no Brasil: cotidiano e vida privada na América Portuguesa. São Paulo: Companhia das Letras, 1997, pp. 41-81.

VIDAL, Laurent. A gênese dos pousos no Brasil moderno. Considerações sobre as formas (urbanas) nascidas da espera. Tempo. Niterói, v. 22, n. 40, p. 400-419, 2016. 